\title{
Changing climate shifts timing of European floods
}

\author{
Günter Blöschl, ${ }^{1 *} \dagger$ Julia Hall, ${ }^{1} \dagger$ Juraj Parajka, ${ }^{1}$ Rui A. P. Perdigão, ${ }^{1}$ Bruno Merz, ${ }^{2}$ \\ Berit Arheimer, ${ }^{3}$ Giuseppe T. Aronica, ${ }^{4}$ Ardian Bilibashi, ${ }^{5}$ Ognjen Bonacci, ${ }^{6}$ \\ Marco Borga, ${ }^{7}$ Ivan Čanjevac, ${ }^{8}$ Attilio Castellarin, ${ }^{9}$ Giovanni B. Chirico, ${ }^{10}$ \\ Pierluigi Claps, ${ }^{11}$ Károly Fiala, ${ }^{12}$ Natalia Frolova, ${ }^{13}$ Liudmyla Gorbachova, ${ }^{14}$ Ali Gül, ${ }^{15}$ \\ Jamie Hannaford, ${ }^{16}$ Shaun Harrigan, ${ }^{16}$ Maria Kireeva, ${ }^{13}$ Andrea Kiss, ${ }^{1}$ \\ Thomas R. Kjeldsen, ${ }^{17}$ Silvia Kohnová, ${ }^{18}$ Jarkko J. Koskela, ${ }^{19}$ Ondrej Ledvinka, ${ }^{20}$ \\ Neil Macdonald, ${ }^{21}$ Maria Mavrova-Guirguinova, ${ }^{22}$ Luis Mediero, ${ }^{23}$ Ralf Merz, ${ }^{24}$ \\ Peter Molnar, ${ }^{25}$ Alberto Montanari, ${ }^{9}$ Conor Murphy, ${ }^{26}$ Marzena Osuch, ${ }^{27}$ \\ Valeryia Ovcharuk, ${ }^{28}$ Ivan Radevski, ${ }^{29}$ Magdalena Rogger, ${ }^{1}$ José L. Salinas, ${ }^{1}$ \\ Eric Sauquet, ${ }^{30}$ Mojca Šraj, ${ }^{31}$ Jan Szolgay, ${ }^{18}$ Alberto Viglione, ${ }^{1}$ Elena Volpi, ${ }^{32}$ \\ Donna Wilson, ${ }^{33}$ Klodian Zaimi, ${ }^{34}$ Nenad Živkovic ${ }^{35}$
}

A warming climate is expected to have an impact on the magnitude and timing of rive floods; however, no consistent large-scale climate change signal in observed flood magnitudes has been identified so far. We analyzed the timing of river floods in Europe over the past five decades, using a pan-European database from 4262 observational hydrometric stations, and found clear patterns of change in flood timing. Warmer temperatures have led to earlier spring snowmelt floods throughout northeastern Europe; delayed winter storms associated with polar warming have led to later winter floods around the North Sea and some sectors of the Mediterranean coast; and earlier soil moisture maxima have led to earlier winter floods in western Europe. Our results highlight the existence of a clear climate signal in flood observations at the continental scale.

R iver flooding affects more people worldwide than any other natural hazard, with an estimated global annual average loss of US \$104 billion (1). Such damages are expected to increase as a result of continued economic growth and climate change $(2,3)$. The intensification of the water cycle due to a warming climate is projected to change the magnitude, frequency, and timing of river floods (3). However, existing studies have been unable to identify a consistent climate change signal in flood magnitudes (4). Identification of a large-scale climate change signal in flood observations has been hampered by the existence of many processes controlling floods, including precipitation, soil moisture, and snow; by nonclimatic drivers of flood change, such as land use change and river training; and by the inconsistency of data sets and their limited spatial extents $(4,5)$. Use of the seasonal timing of floods as a fingerprint of climate effects on floods may be a way to avoid some of those complications $(6,7)$. For example, in cold regions, earlier snowmelt due to warmer temperatures leads to earlier spring floods (6), and this climate-related signal may be less confounded by nonclimatic drivers than flood magnitudes themselves because of the strong seasonality of climate. The changing timing of floods has been studied at local scale in Nordic and Baltic countries (8-10), but no consistent analysis exists at the European scale.

Here, we analyzed a large data set of flood observations in Europe to assess whether a changing climate has shifted the timing of river floods during the past five decades. Our analysis is based on river discharge or water-level observations from 4262 hydrometric stations in 38 European countries for the period 1960-2010 (table S1). For each station, we use a series consisting of the dates of occurrence of the highest peak in any calendar year. We define the average timing of the floods by the average date on which floods have occurred during the observation period. We then use the Theil-Sen slope estimator (11) to estimate the trend in the timing of the floods for stations with at least 35 years of data, and apply a 10-year moving-average filter to estimate the long-term evolution. Finally, we analyze the change signal of three potential drivers of flood changes in a similar fashion: (i) the middle date of the maximum 7-day precipitation; (ii) the middle day of the month with the highest soil moisture; and (iii) the middle day of the first 7 days in a year with air temperature above $0^{\circ} \mathrm{C}$ as a proxy for spring snowmelt and snowfall-to-rain transition (see supplementary materials).

Our data show a clear shift in the timing of floods in Europe during the past 50 years (Fig. 1). The regionally interpolated trend patterns shown in Fig. 1 range from -13 days per decade toward earlier floods to +9 days toward later floods, which translates into total shifts of -65 and +45 days, respectively, of linear trends over the entire 50-year period. The local, station-specific, trends (fig. S2) are larger, but these trend sizes reflect smallerscale rather than regional-scale processes. The changes are most consistent in northeastern Europe (Fig. 1, region 1), where $81 \%$ of the stations show a shift toward earlier floods ( $50 \%$ of the stations by more than -8 days per 50 years) (fig. S2). The changes are largest in western Europe along the North Atlantic coast from Portugal to England (region 3), where $50 \%$ of the stations show a shift toward earlier floods by at least -15 days per 50 years $(25 \%$ of the stations by more than -36 days per 50 years). Around the North Sea (region 2; southwestern Norway, the Netherlands, Denmark, and Scotland), $50 \%$ of the stations show a shift toward later floods by more than +8 days per 50 years. In some parts of the Mediterranean coast (region 4; northeastern Adriatic coast, northeastern Spain), there is a shift toward later floods (50\% of the stations by more than +5 days per 50 years). Apart from the large-scale change patterns described

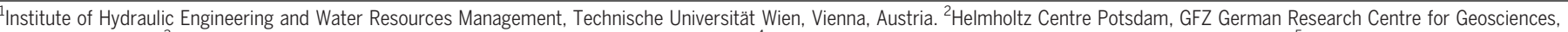

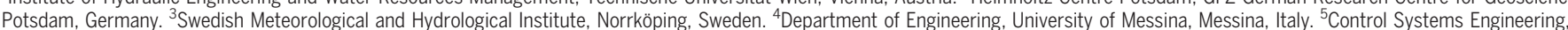

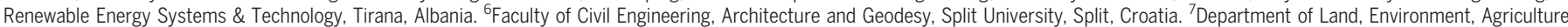
and Forestry, University of Padova, Padua, Italy. ${ }^{8}$ Department of Geography, Faculty of Science, University of Zagreb, Zagreb, Croatia. ${ }^{9}$ Department of Civil, Chemical, Environmental and

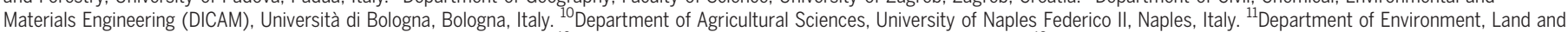
Infrastructure Engineering (DIATI), Politecnico di Torino, Turin, Italy. ${ }^{12}$ Lower Tisza District Water Directorate, Szeged, Hungary. ${ }^{13}$ Department of Land Hydrology, Lomonosov Moscow State University, Moscow, Russia. ${ }^{14}$ Department of Hydrological Research, Ukrainian Hydrometeorological Institute, Kiev, Ukraine. ${ }^{15}$ Department of Civil Engineering, Dokuz Eylul University, Izmir, Turkey. ${ }^{16}$ Centre for Ecology \& Hydrology, Wallingford, Oxfordshire, UK. ${ }^{17}$ Department of Architecture and Civil Engineering, University of Bath, Bath, UK. ${ }^{18}$ Department of Land and Water

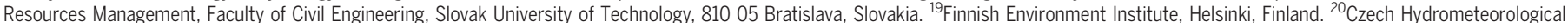

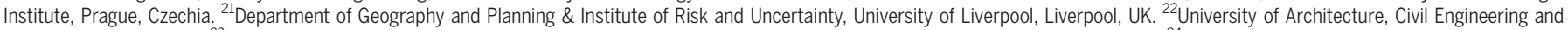

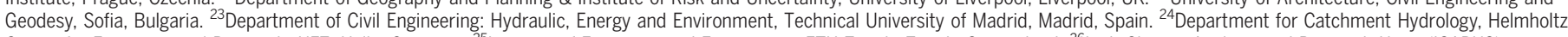
Centre for Environmental Research-UFZ, Halle, Germany. ${ }^{25}$ Institute of Environmental Engineering, ETH Zürich, Zürich, Switzerland. ${ }^{26}$ Irish Climate Analysis and Research Units (ICARUS), Department of Geography, Maynooth University, Ireland. ${ }^{27}$ Department of Hydrology and Hydrodynamics, Institute of Geophysics, Polish Academy of Sciences, Warsaw, Poland.

${ }^{28}$ Hydrometeorological Institute, Odessa State Environmental University, Odessa, Ukraine. ${ }^{29}$ Institute of Geography, Faculty of Natural Sciences and Mathematics, Ss. Cyril and Methodius

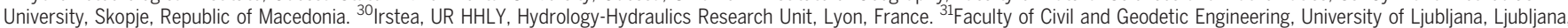

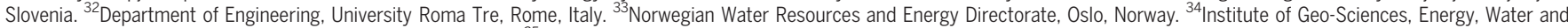
Environment, Polytechnic University of Tirana, Tirana, Albania. ${ }^{35}$ Faculty of Geography, University of Belgrade, Belgrade, Serbia.

*Corresponding author. Email: bloeschl@hydro.tuwien.ac.at †These authors contributed equally to this work. 
for the four regions above, smaller-scale patterns of changes in flood timing can also be identified.

To infer the causes of these changes in timing, we focused on six subregions or hotspots where changes in flood timing are particularly clear (fig. S2 and table S2). Because floods are the result of the seasonal interplay of precipitation, soil moisture, and snow processes (12), we analyzed the temporal evolutions of these variables and compared them to those of the floods (Fig. 2). In southern Sweden (Fig. 2A) and the Baltics (Fig. $2 \mathrm{~B}$ ), floods are mainly due to spring snowmelt $(9,10)$. The temporal evolution of flood timing therefore closely follows that of snowmelt, shifting from late March to February (green and orange lines in Fig. 2, A and B). Earlier snowmelt is known to be driven by both local temperature increases and a decreasing frequency of advection of arctic air masses (13). The Baltics are topographically less shielded than southern Sweden from these air masses; this is reflected by larger variations in the timing of snowmelt in the 1990s. In southwestern Norway (Fig. 2C), precipitation maxima at the end of the year generate floods around the same time, because the prevalent shallow soils have only limited subsurface water storage capacity. Changes in the North Atlantic Oscillation (NAO) since 1980 (14) may have resulted in a delayed arrival of heavy winter precipitation, with maxima shifting from October to December. These NAO anomalies have been less pronounced since the early 2000s. The floods follow closely the timing of extreme precipitation (Fig. 2C), which strongly suggests a causal link. The changes in the NAO may be related to polar warming, among many other factors, although the role of anthropogenic effects is still uncertain $(15,16)$. In southern England (Fig. 2D), subsurface water storage capacity tends to be much larger than in coastal Norway. The maximum rainfall, which occurs in autumn, therefore tends to get stored, and soil moisture and groundwater tables continuously increase until they reach a maximum in winter. Sustained winter rainfall on saturated soils then produces the largest floods in winter. As a result, the flood timing in southern England is more closely associated with the timing of maximum soil moisture than with the timing of extreme precipitation (17). The variations in flood timing in northwestern Iberia (Fig. 2E) are similar to those of southern England, although precipitation in Iberia occurs more in the winter, so extreme precipitation and maximum soil moisture (driven by sustained precipitation) are more closely aligned. Along the northern Adriatic coast (Fig. 2F), largescale effects of the Atlantic Ocean influence Adriatic mesoscale cyclonic activity, which produces heavy precipitation toward the end of the year (18). Meridional shifts in storm tracks have increased atmospheric flow from the Atlantic to the Mediterranean in winter (19), leading to later extreme precipitation and floods in the season (Fig. 2F).

The spatial pattern of the average within-year flood timing between 1960 and 2010 (Fig. 3) provides further support for the interpretation of trends in flood timing across Europe. The average

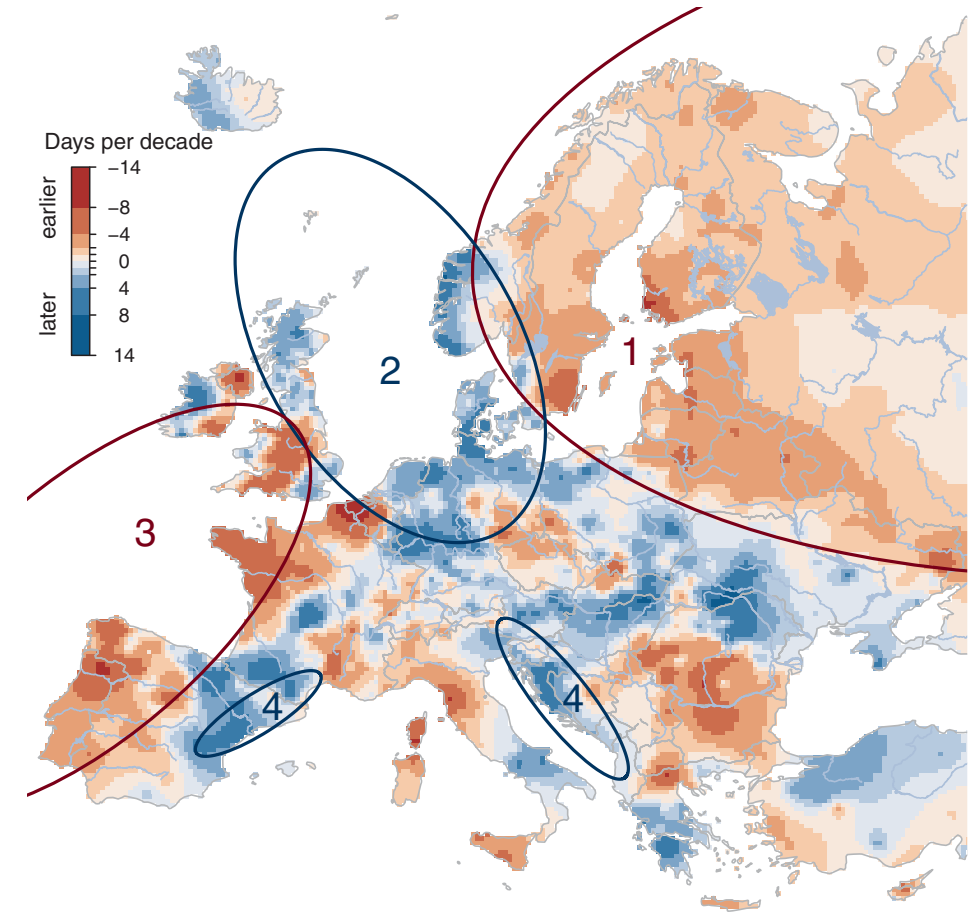

Fig. 1. Observed trends of river flood timing in Europe, 1960-2010. The color scale indicates earlier or later floods (days per decade). Regions with distinct drivers: Region 1, northeastern Europe (earlier snowmelt); region 2, North Sea (later winter storms); region 3, western Europe along the Atlantic coast (earlier soil moisture maximum); region 4, parts of the Mediterranean coast (stronger Atlantic influence in winter).
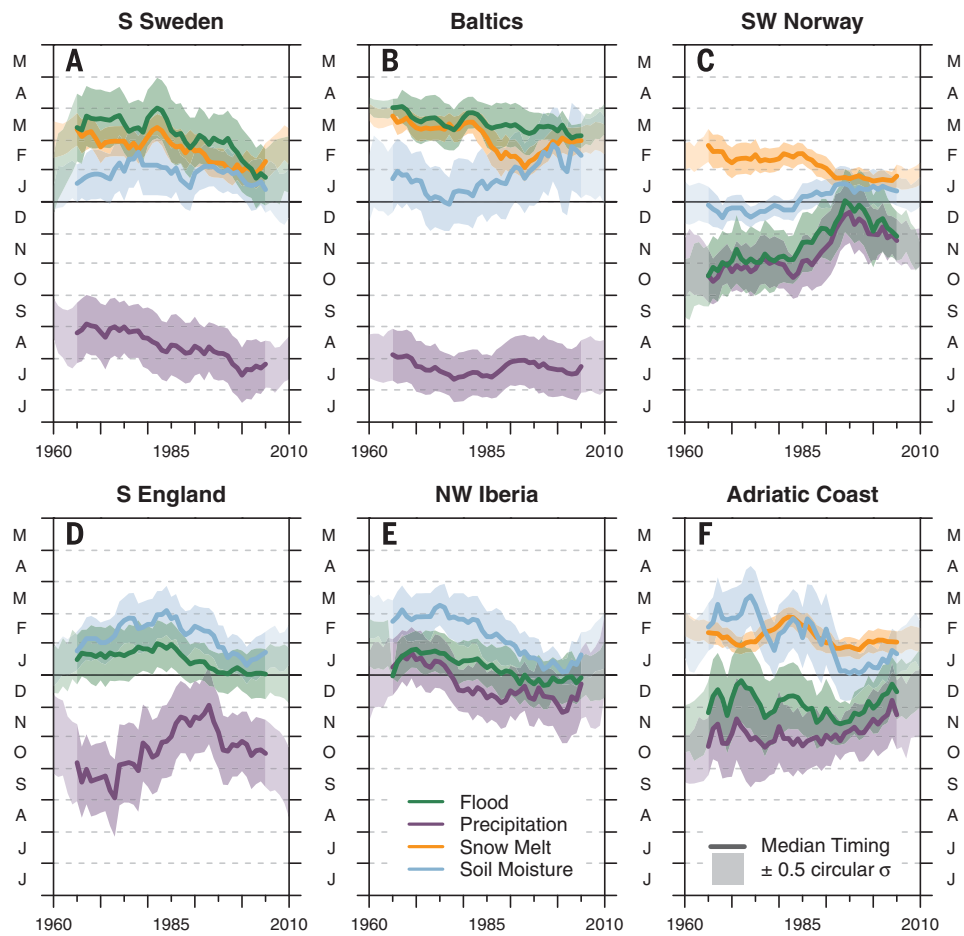

Fig. 2. Long-term temporal evolution of timing of floods and their drivers for six hotspots in Europe. (A) Southern Sweden; (B) Baltics; (C) southwestern Norway; (D) southern England; (E) northwestern Iberia; (F) Adriatic coast. Solid lines show median timing over the entire hotspot; shaded bands indicate variability of timing within the year ( \pm 0.5 circular standard deviations). Green, timing of observed floods; purple, 7-day maximum precipitation; orange, snowmelt indicator; blue, timing of modeled maximum soil moisture. All data were subjected to a 10-year moving average filter. Vertical axes show month of the year (June to May). 


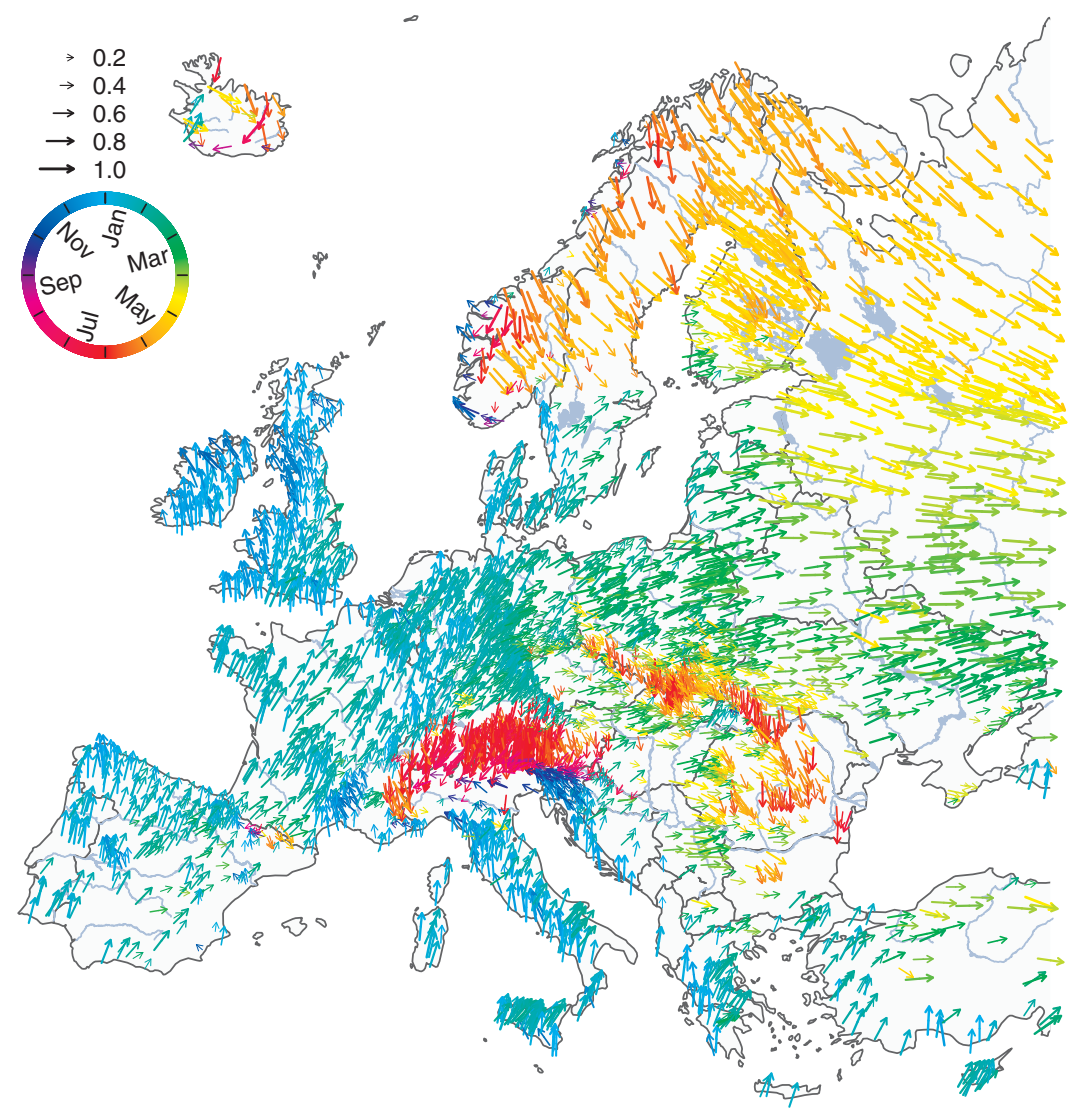

Fig. 3. Observed average timing of river floods in Europe, 1960-2010. Each arrow represents one hydrometric station $(n=4062)$. Color and arrow direction indicate the average timing of floods, as indicated by the circular color scale (light blue, winter floods; green to yellow, spring floods; orange to red, summer floods; purple to dark blue, autumn floods). Lengths of the arrows indicate the concentration of floods within a year ( 0 , evenly distributed; 1 , all floods occur on the same date).

timing of the floods varies gradually both from the west to the east because of increasing continentality (distance from the Atlantic) and from the south to the north because of the increasing influence of snow-related processes. The effect of snow storage and melt at high altitudes-for example, in the Alps and the Carpathians (orange to red arrows in Fig. 3)-is superimposed on this spatial pattern. The spatial patterns of the average timing of potential drivers, and their trends, are shown in figs. S3 to S5.

Throughout northeastern Europe (Fig. 1, region 1), spring occurrence of snowmelt and floods (yellow and green arrows in figs. S3 and S4A) combined with a warmer climate (fig. S4A) has led to earlier floods. In the region around the North Sea (Fig. 1, region 2), extreme precipitation and floods in the winter (blue arrows in Fig. 3 and fig. S3A) combined with a shift in the timing of extreme winter precipitation (fig. S3B) has led to later floods. In western Europe (Fig. 1, region 3), winter occurrence of soil moisture maxima and floods (blue arrows in Fig. 3 and fig. S5A) combined with a shift in the timing of soil moisture maxima (fig. S5B) has led to earlier floods. Although region 3 shows a consistent behavior in flood timing changes, closely aligned with those of soil moisture, the effects of changing storm tracks on precipitation are different in southern England and northwestern Iberia because of the opposite effects of the NAO.

If the trends in flood timing continue, considerable economic and environmental consequences may arise, because societies and ecosystems have adapted to the average within-year timing of floods. Later winter floods in catchments around the North Sea, for example, would lead to softer ground for spring farming operations, higher soil compaction, enhanced erosion, and direct crop damage, thereby reducing agricultural productivity (20). Spring floods occurring earlier in the season in northeastern Europe may limit the replenishment of reservoirs if managers expect later floods that never arrive, with substantial reductions in water supply, irrigation, and hydropower generation (21). Our flood timing observations at the continental scale also enable the identification of a clear climate change signal that could not be obtained by earlier studies based on flood magnitude data $(4,5,22)$.

\section{REFERENCES AND NOTES}

1. United Nations Office for Disaster Risk Reduction (UNISDR) Making Development Sustainable: The Future of Disaster Risk Management. Global Assessment Report on Disaster Risk Reduction (2015); www.unisdr.org/we/inform/publications/ 42809.

2. H. C. Winsemius et al., Nat. Clim. Chang. 6, 381-385 (2016).

3. IPCC, Managing the Risks of Extreme Events and Disasters to Advance Climate Change Adaptation. A Special Report of Working Groups I and II of the Intergovernmental Panel on Climate Change (Cambridge Univ. Press, 2012).

4. J. Hall et al., Hydrol. Earth Syst. Sci. 18, 2735-2772 (2014).

5. Z. Kundzewicz, Changes in Flood Risk in Europe (International Association of Hydrological Sciences, 2012).

6. J. Parajka et al., J. Hydrol. 394. 78-89 (2010).

7. R. Merz, G. Blöschl, Water Resour. Res. 39, 1340 (2003).

8. D. Wilson, H. Hisdal, D. Lawrence, J. Hydrol. 394, 334-346 (2010).

9. B. Arheimer, G. Lindström, Hydrol. Earth Syst. Sci. 19, 771-784 (2015).

10. D. Sarauskiene, J. Kriauciuniene, A. Reihan, M. Klavins, J. Environ. Eng. Landsc. 23, 28-38 (2015).

11. P. K. Sen, J. Am. Stat. Assoc. 63, 1379-1389 (1968).

12. M. Sivapalan, G. Blöschl, R. Merz, D. Gutknecht, Water Resour. Res. 41, W06012 (2005).

13. A. Draveniece, Boreal Environ. Res. 14, 89-99 (2009); www.borenv net/BER/pdfs/ber14/ber14-089.pdf.

14. J. W. Hurrell, H. Van Loon, Clim. Change 36, 301-326 (1997).

15. N. P. Gillett et al., Nat. Geosci. 1, 750-754 (2008).

16. E. Hanna, T. E. Cropper, P. D. Jones, A. A. Scaife, R. Allan, Int. J. Climatol. 35, 2540-2554 (2015).

17. A. C. Bayliss, R. C. Jones, Peaks-over-Threshold Flood Database: Summary Statistics and Seasonality (Institute of Hydrology, Wallingford, UK, 1993)

18. B. Ivančan-Picek, K. Horvath, N. Mahović, M. Gajić-Čapka, Nat. Hazards 72, 1231-1252 (2014).

19. E. Xoplaki, J. F. González-Rouco, J. Luterbacher, H. Wanner, Clim. Dyn. 23, 63-78 (2004).

20. S. Klaus, H. Kreibich, B. Merz, B. Kuhlmann, K. Schröter, Environ. Earth Sci. 75, 1289 (2016).

21. T. P. Barnett, J. C. Adam, D. P. Lettenmaier, Nature 438 , 303-309 (2005).

22. M. Mudelsee, M. Börngen, G. Tetzlaff, U. Grünewald, Nature 425, 166-169 (2003).

\section{ACKNOWLEDGMENTS}

Supported by ERC Advanced Grant "FloodChange," project no. 291152; the Austrian Science Funds (FWF) as part of the Doctoral Programme on Water Resource Systems (W1219-N22); the EU FP7 project SWITCH-ON (grant 603587); and Russian Science Foundation project no. 14-17-00155. We acknowledge the involvement in the data screening process of C. Álvaro Díaz,

I. Borzi, E. Diamantini, K. Jeneiová, M. Kupfersberger, and $S$. Mallucci during their stays at the Vienna University of Technology. We thank L. Gaál and D. Rosbjerg for contacting Finish and Danish data holders, respectively; A. Christofides for pointing us to the Greek data source; B. Renard (France), T. Kiss (Hungary). W. Rigott (South Tyrol, Italy), G. Lindström (Sweden), and P. Burlando (Switzerland) for assistance in preparing and/or providing data or metadata from their respective regions; and $\mathrm{B}$. Lüthi and $\mathrm{Y}$. Hundecha for preparing supporting data that are not part of the paper, to cross-check the results. The flood date data used in this paper can be downloaded from www.hydro.tuwien.ac.at/fileadmin/ mediapool-hydro/Downloads/Data.zip. The precipitation and temperature data can be downloaded from www.ecad.eu/ download/ensembles/ensembles.php. The soil moisture data can be downloaded from www.esrl.noaa.gov/psd.

\section{SUPPLEMENTARY MATERIALS}

www.sciencemag.org/content/357/6351/588/suppl/DC1

Materials and Methods

Supplementary Text

Figs. S1 to S5

Tables S1 and S2

References (23-41)

17 March 2017; accepted 30 June 2017

10.1126/science.aan2506 


\section{Science}

\section{Changing climate shifts timing of European floods}

Günter Blöschl, Julia Hall, Juraj Parajka, Rui A. P. Perdigão, Bruno Merz, Berit Arheimer, Giuseppe T. Aronica, Ardian Bilibashi, Ognjen Bonacci, Marco Borga, Ivan Canjevac, Attilio Castellarin, Giovanni B. Chirico, Pierluigi Claps, Károly Fiala, Natalia Frolova, Liudmyla Gorbachova, Ali Gül, Jamie Hannaford, Shaun Harrigan, Maria Kireeva, Andrea Kiss, Thomas R. Kjeldsen, Silvia Kohnová, Jarkko J. Koskela, Ondrej Ledvinka, Neil Macdonald, Maria Mavrova-Guirguinova, Luis Mediero, Ralf Merz, Peter Molnar, Alberto Montanari, Conor Murphy, Marzena Osuch, Valeryia Ovcharuk, Ivan Radevski, Magdalena Rogger, José L. Salinas, Eric Sauquet, Mojca Sraj, Jan Szolgay, Alberto Viglione, Elena Volpi, Donna Wilson, Klodian Zaimi and Nenad Zivkovic

Science 357 (6351), 588-590.

DOI: $10.1126 /$ science.aan2506

\section{Flooding along the river}

Will a warming climate affect river floods? The prevailing sentiment is yes, but a consistent signal in flood magnitudes has not been found. Blöschl et al. analyzed the timing of river floods in Europe over the past 50 years and found clear patterns of changes in flood timing that can be ascribed to climate effects (see the Perspective by Slater and Wilby). These variations include earlier spring snowmelt floods in northeastern Europe, later winter floods around the North Sea and parts of the Mediterranean coast owing to delayed winter storms, and earlier winter floods in western Europe caused by earlier soil moisture maxima. Science, this issue p. 588 see also p. 552

ARTICLE TOOLS

SUPPLEMENTARY MATERIALS

RELATED

CONTENT

REFERENCES

PERMISSIONS http://science.sciencemag.org/content/357/6351/588

http://science.sciencemag.org/content/suppl/2017/08/09/357.6351.588.DC1

http://science.sciencemag.org/content/sci/357/6351/552.full

This article cites 27 articles, 0 of which you can access for free http://science.sciencemag.org/content/357/6351/588\#BIBL

http://www.sciencemag.org/help/reprints-and-permissions

Use of this article is subject to the Terms of Service

Science (print ISSN 0036-8075; online ISSN 1095-9203) is published by the American Association for the Advancement of Science, 1200 New York Avenue NW, Washington, DC 20005. The title Science is a registered trademark of AAAS.

Copyright (C) 2017 The Authors, some rights reserved; exclusive licensee American Association for the Advancement of Science. No claim to original U.S. Government Works 